\title{
Experience of percutaneous endoscopic gastrostomy in children with Crohn's disease
}

\author{
Michael Cosgrove, Huw R Jenkins
}

\begin{abstract}
Enteral nutrition is an important mode of treatment for Crohn's disease in children. Percutaneous endoscopic gastrostomy has been little used, even though it can facilitate the administration of an unpalatable elemental diet to an anorexic, undernourished patient. Its use is reported in 10 children with Crohn's disease. The gastrostomy was found to be more acceptable than a nasogastric tube and was associated with only minor complications. As a consequence of improved delivery of enteral nutrition, in the year after the insertion of the gastrostomy there was a reduction in prednisolone dosage in all patients, with six patients being able to stop prednisolone completely. The SD score for height also improved significantly. It is suggested that percutaneous endoscopic gastrostomy is both useful and safe in the management of Crohn's disease in children, particularly when compliance with an elemental diet is likely to be poor.

(Arch Dis Child 1997;76:141-143)
\end{abstract}

Keywords: Crohn's disease; percutaneous endoscopic gastrostomy; enteral nutrition.

Nutrition plays a critical part in the management of Crohn's disease in children, not only because malnutrition and growth failure are common at presentation, ${ }^{1}$ but also because an elemental diet has been shown to be as effective as steroids in inducing the remission of active disease while avoiding the negative effects on growth. ${ }^{2}$ One of the main problems associated with elemental feeds is unpalatability, and consequently it may be difficult to persuade children and adolescents to consume the large amounts required to reverse growth failure and weight loss. Nasogastric tube feeding has been used for this reason, ${ }^{3}$ but has the disadvantage of being uncomfortable, particularly if tubes are being passed every night, and embarrassing for the self conscious child or adolescent if the tube is left in situ during the day.

A gastrostomy can overcome this problem as Department of Child Hospital of Wales, Cardiff

M Cosgrove

H R Jones

Correspondence to: Dr M Cosgrove, Department of Child Health, Singleton Hospital, Sketty, Swansea SA2 8QA.

Accepted 4 November 1996 formation in patients with Crohn's disease, which may have discouraged some doctors from using the technique, although Israel and Hassall have reported their experience using either percutaneous endoscopic gastrostomy or surgically placed gastrostomy in children with growth arrest due to Crohn's disease, finding that it was safe and well tolerated. ${ }^{5}$ We now report our own experience of the use of percutaneous endoscopic gastrostomy in children with Crohn's disease with reference to the patients' preference, the effects on growth and required corticosteroid dosage, and complications.

\section{Patients and methods}

Between October 1990 and January 1994, 10 children (six girls, four boys) with the diagnosis of Crohn's disease under the care of the paediatric gastroenterology unit, University Hospital of Wales, had a percutaneous endoscopic gastrostomy (Freka, Fresinius) inserted to facilitate the use of an elemental diet as part of their management. An elemental diet was prescribed to attempt to reverse poor growth or to reduce the steroid requirements of the patients. All patients had attempted to take the elemental diet by mouth, but found it too unpalatable to drink the prescribed amounts. Two patients had previously been fed an elemental diet via a nasogastric tube; the other eight were all offered the choice of a percutaneous endoscopic gastrostomy or a nasogastric tube, and after an explanation of both methods selected the percutaneous endoscopic gastrostomy.

The diagnosis of Crohn's disease had in all instances been made from a histological examination of specimens obtained at colonoscopy, with an assessment of small intestinal involvement made from barium meal and follow through. All patients had small bowel disease, with six patients also having colonic involvement. The median age at diagnosis was 12.5 years (range $7.3-16.1$ years).

At the time of insertion of the percutaneous endoscopic gastrostomy the median age was 14.4 years (range 12.4-16.1 years), with the median time period between diagnosis and insertion being 0.8 years (range $0-6.7$ years). One patient's nutritional status was so poor and potential linear growth so limited that a percutaneous endoscopic gastrostomy was inserted within two weeks of diagnosis. The percutaneous endoscopic gastrostomy was inserted under general anaesthesia using the technique described by Ponsky et al. ${ }^{6}$ There was no endoscopic evidence of gastric mucosal inflammation in any of the patients. All patients received Elemental 028 (Scientific Hospital Supplies) feed, given via the percutaneous 
Table 1 Prednisolone dose ( $\mathrm{mg} / \mathrm{kg} / \mathrm{day})$ and SD scores for height immediately before and one year after insertion of percutaneous endoscopic gastrostomy in 10 children with Crohn's disease

\begin{tabular}{llllll}
\hline & \multicolumn{2}{l}{ Prednisolone dose } & & \multicolumn{2}{l}{ Height SD score } \\
\cline { 2 - 3 } \cline { 5 - 6 } Patient No & Before insertion & After insertion & & Before insertion & After insertion \\
\hline 1 & 0.38 & 0.08 & -1.2 & -1.1 \\
2 & 0.26 & 0.12 & -0.9 & -0.6 \\
3 & 0.60 & 0.08 & -1.4 & -0.7 \\
4 & 0.31 & 0.04 & 0.2 & 0.5 \\
5 & 0.50 & 0 & NA & NA \\
6 & 0.08 & 0 & -2.0 & -2.5 \\
7 & 0.39 & 0 & -3.0 & -2.3 \\
8 & 0.15 & 0 & -4.1 & -2.3 \\
9 & 2.27 & 0 & -4.6 & -3.6 \\
10 & 0.72 & 0 & -1.3 & -1.0 \\
\hline
\end{tabular}

$\mathrm{NA}=$ not available. four patients while the percutaneous endoscopic gastrostomy was in situ; one of these patients also reported bloating during feeds, as described earlier, interfering with her ability to take the required amount of feed. There were no problems of accidental removal or blockage of the percutaneous endoscopic gastrostomy tubes and no related fistulas were encountered among our patients.

The only related serious complication occurred after the attempted removal of the percutaneous endoscopic gastrostomy in one child (patient 1) who no longer required enteral feeding. It had been our practice to simply cut the external part of the percutaneous endoscopic gastrostomy tube and allow the inner flange to pass out via the rectum if there had been no clinical suspicion of intestinal strictures. In this child the flange failed to appear in the faeces and two weeks later she presented with features of subacute obstruction. Imaging showed the flange to be impacted in a previously unsuspected stricture and she required an operation to remove the flange and stricturoplasty. Since that time we have always removed the gastrostomy endoscopically, retrieving the flange at the same time.

\section{Discussion}

Improving nutritional status is often an important part of the management of Crohn's disease in children, but may be hampered by anorexia and the unpalatability of elemental formulas, large volumes of which are usually required to satisfy nutritional requirements. If these large volumes cannot be managed by mouth, nasogastric tube feeding has been the preferred option for supplementary feeds, but recent evidence suggests that percutaneous endoscopic gastrostomy may be equally safe and effective. ${ }^{5}$

Our experience has shown that among a group of young people with Crohn's disease the percutaneous endoscopic gastrostomy was preferred to nasogastric tube feeding as a route for delivering an elemental formula and, despite its more invasive nature, this is perhaps not too surprising it is completely hidden during normal daily activities and does not require re-passing nightly.

Complications during use were minor and easily treated. The potential increased risk of fistula formation is a justified concern and Israel and Hassall reported one patient who required suturing of a small gastrocutaneous fistula after percutaneous endoscopic gastrostomy removal. ${ }^{5}$ The technique of insertion, involving the visualisation of the gastric mucosa before selecting the site to form the gastrostomy, allows the operator to avoid areas of obvious inflammation and this may reduce the risk. We appreciate that a normal macroscopic appearance of the mucosa does not exclude histological evidence of Crohn's disease and theoretically there is a risk of inserting the percutaneous endoscopic gastrostomy through inflamed tissue. In our experience, however, fistula formation was not encountered and we have been impressed by the reduction in steroid dose and improvements in growth and general sense of wellbeing in our
Minor complications of local sepsis and excess granulation tissue were experienced in 
patients after the insertion of the percutaneous endoscopic gastrostomy, and the improved compliance with nutritional treatment.

Israel and Hassall restricted percutaneous endoscopic gastrostomy to patients with growth failure secondary to Crohn's disease. ${ }^{5}$ Although our patients as a group were short, with a median SD score of -1.4 at the time of percutaneous endoscopic gastrostomy insertion, some patients were not particularly short nor had failing growth. Even in these patients, however, the benefit of the enteral feeding facilitated by percutaneous endoscopic gastrostomy can be seen in the subsequent reduction in prednisolone dosage, which may have itself contributed to the improvement in linear growth. Our policy has been to consider percutaneous endoscopic gastrostomy for any patient with Crohn's disease who requires an elemental diet and finds the taste so unpleasant as to jeopardise compliance. The recent finding by Wilschanski et al that supplementary enteral nutrition used after the successful treatment of active Crohn's disease by exclusive enteral nutrition, as we used in our patients, prolongs remission and improves linear growth gives further justification to our policy. ${ }^{7}$ Polk et al also showed the benefits of the intermittent administration of enteral nutrition on growth and disease activity in children with Crohn's disease. ${ }^{8}$ A percutaneous endoscopic gastrostomy could allow treatment to be given in this way to children who preferred percutaneous endoscopic gastrostomy to a nasogastric tube.

It is possible that if the finding of studies in adults ${ }^{9}$ and children ${ }^{10}$ which suggest that the enteral feed used for the treatment of active
Crohn's disease can be polymeric rather than elemental are confirmed by larger studies, then the problem of compliance may be less important. Polymeric formulas are generally more palatable, but large volumes may still be required and remain difficult to take by mouth. In the meantime we suggest that percutaneous endoscopic gastrostomy may be of great value in the nutritional management of children with Crohn's disease and appears to be a safe and well tolerated procedure.

1 Kirschner BS, Voinchet O, Rosenberg IH. Growth retardation in inflammatory bowel disease. Gastroenterology 1978;75:504-11.

2 Sanderson IR, Udeen S, Davies PSW, Savage MO, WalkerSmith JA. Remission induced by an elemental diet in small bowel Crohn's disease. Arch Dis Child 1987;62:123-7.

3 Belli DC, Seidman E, Bouthillier L, et al. Chronic intermittent elemental diet improves growth failure in children with Crohn's disease. Gastroenterology 1988;94:603-10.

4 Marin OE, Glassman MS, Schoen BT. Safety and efficacy of percutaneous endoscopic gastrostomy in children. $A m \mathcal{F}$ Gastroenterol 1994;89:357-61.

5 Israel DM, Hassall E. Prolonged use of gastrostomy for enteral hyperalimentation in children with Crohn's disease. Am 7 Gastroenterol 1995;90:1084-8.

6 Ponsky JL, Gauderer MWL, Stellato TL, Aszodi A. Percutaneous approaches to enteral alimentation. $A m \mathcal{F}$ Surg 1985;149:102-5.

7 Wilschanski M, Sherman P, Pencharz P, Davis L, Corey M, Griffiths A. Supplementary enteral nutrition maintains remission in paediatric Crohn's disease. Gut 1996;38:543

8 Polk DB, Hattner JA, Kerner JA Jr. Improved growth and disease activity after intermittent administration of a defined formula diet in children with Crohn's disease. 7 Parenteral Enteral Nutr 1992;16:499-504.

9 Rigaud D, Cosnes J, Le Quintrec Y, René E, Gendre JP, Mignon M. Controlled trial comparing two types of enteral nutrition in treatment of active Crohn's disease: elemental $v$ polymeric diet. Gut 1991;32:1492-7.

10 Beattie RM, Schiffrin EJ, Donnet-Hughes A, et al. Polymeric nutrition as the primary therapy in children with small bowel Crohn's disease. Aliment Pharmacol Ther 1994; 8:609-15. 